\title{
Factors Influencing the Machinability during Turning Sinter-Hardened Cu-Ni-Mo Based Steel: Dependency on Cutting Speed, Feed Rate, and Cutting Depth
}

\author{
N. Beköz Ullen*, S.M.A. Hasak** and M.H. Dirikolu** \\ *Department of Metallurgical and Materials Engineering, Faculty of Engineering, Istanbul University-Cerrahpaşa, Istanbul, 34320, Turkey \\ **Department of Mechanical Engineering, Faculty of Engineering, Istanbul University Cerrahpaşa, Istanbul, 34320, Turkey \\ *Corresponding Author: nbekoz@istanbul.edu.tr
}

Submitted: $15 / 11 / 2019$

Revised: $\quad 09 / 12 / 2019$

Accepted: 06/01/2020

\begin{abstract}
Machinability of sintered parts is a complex phenomenon influenced by a number of factors, including workpiece and tool properties, cutting conditions, and cutting parameters. A better understanding of the influence of all these parameters on the machinability of sinter-hardened $\mathrm{Cu}-\mathrm{Ni}$-Mo based steels is essential. This work uses an output matrix of surface roughness, chip formation, cutting forces, and tool wear to assess the machinability of sintered parts. Cutting speeds of 50,150 , and $250 \mathrm{~m} / \mathrm{min}$, feed rates of $0.05,0.1$, and $0.15 \mathrm{~mm} / \mathrm{rev}$, and cutting depths of $0.2,0.4$, and $0.6 \mathrm{~mm}$ were systematically used as cutting parameters. The results indicated that short spiral chips were formed in all cutting parameters and that the higher feed rates and cutting depth increase the forces and deteriorate surface quality. The increase in cutting speed increases the forces, while linearly decreasing the tool life; however, it has a positive effect on the surface finish.
\end{abstract}

Keywords: Machinability; Powder metallurgy; Surface roughness; Tool wear; Chip formation; Cutting force.

\section{INTRODUCTION}

Powder metallurgy (PM) is a near-net shape manufacturing process that requires few secondary operations. However, due to technical limitations, many PM parts require to be subjected to some machining processes for proper tolerance, or they include geometrical characteristics, which cannot be molded by pressing process (RobertPerron et al., 2005). Investigation of the PM market reveals that about $60 \%$ of all components need some kind of machining operation. These operations can be responsible for up to $20 \%$ percent of the total production cost of a component (Höganäs, 2004-a). PM parts normally show lower machining behavior than wrought materials, and their machining costs are more expensive than expected (M'Saoubi et al., 2014). The poor machinability of PM parts is usually associated with one or more of these three factors: interrupted cutting, lower thermal conductivity due to the presence of porosity, and hard phases (Causton and Schade, 2003; Robert-Perron et al., 2007-a). Each of these factors used to explain the differences in PM machinability has been evaluated and discussed further by large numbers of authors (Alizadeh, 2008; Klink et al., 2011; Selvakumar et al., 2012; Smith, 1988; Šalak et al., 2005). These properties of PM parts cause temperature to increase on the tool/chip interface and lead to wear mechanisms on the cutting tool such as adhesive, abrasive, diffusion, and deformation (Trent and Wright, 2000). Machining performance obtained from the application of PM technology on production plays an important role in receiving economic benefits (Armarego et al., 2001). Furthermore, only a limited part of the research and development efforts, which have been published regarding PM science and technology, has been reported. The waste from chips in the machining of 
structural parts is typically at the ratio of $40-60 \%$. But this ratio is $10-15 \%$ maximum at PM parts machining (Alizadeh, 2008). These results also emphasize the environmental and economic importance of PM technology with respect to machinability. Machining in PM should be considered as a special machining that extends the application range of PM parts to more advanced ones, which are the area for conventional machining routes from wrought steels (Alizadeh, 2008). Turning and drilling are the most commonly used cutting methods for machining of PM parts (Alizadeh, 2008; Armarego et al., 2001; Causton and Schade, 2003; Höganäs, 2004-a; Klink et al., 2011; M'Saoubi et al., 2014; Robert-Perron et al., 2007-a; Selvakumar et al., 2012; Smith, 1988; Šalak et al., 2005; Trent and Wright, 2000). The face turning process is one of the short-term tests to test the machinability of steels. Many researchers (Armarego et al., 2001; Jakubéczyová and Fáberová, 2002; Lalbondre et al., 2013; Šalak et al., 2006) have successfully demonstrated the method of turning in their studies to evaluate the machinability of PM steels. The machinability of a PM component depends on the workpiece and tool material characteristics, such as composition expressed in microstructure, mechanical, and physical properties, and the cutting conditions and machining parameters, such as tool material and tool geometry. Measures for improvement the machinability of PM steel parts are the aim of systematic research efforts and are of practical experiences in this area (Hamiuddin and Murtaza, 2001). As described in many studies, the machining of PM steels can be improved by several techniques including (a) material properties such as free-machining additives-machining aids, pore filling-infiltration, impregnation; (b) manufacturing processes such as microstructure modification, annealing, and presintering; (c) conditions affecting the machining process such as cutting tool features and cutting conditions. Machining operations should be the goal of focused collaboration between PM part manufacturers and cutting tool manufacturers (Alizadeh, 2008). Green machining could also be an alternative; however, after sintering, changes in shape and dimensions generally impair the quality of the machined surface ( Blais et al., 2001; Höganäs, 2004-a; Robert-Perron et al., 2007-b). Influence of additive on the mechanical properties indicates that nearly all additives decrease the mechanical properties (Höganäs, 2004-b). For selecting the appropriate tool and machining parameters, knowledge of tool material and affecting loads is necessary together with the analysis of wear mechanisms, and with the knowledge of the workpiece material properties, which should be characterized in more detail for the machining process, and their interaction (Šalak et al., 2006). Recent studies on machining have shown that the cutting parameters have a major effect on the properties of finished parts (Blais et al., 2001). The cutting parameters examined in this study such as the cutting speed (V), the feed rate (f), and the cutting depth (a) show different effects on the machinability properties, such as the chip formation, tool life, cutting forces, and surface integrity (Isik, 2007). It is undoubtedly known that all improvements on machinability of PM parts will be stepped up further by the optimization of the cutting parameters. Effects of machining parameters on sintered steels should be investigated in detail to develop the machinability with a scientific perspective. The various researches on machinability of PM materials have been reviewed while doing this study, but little efforts have been made in developing the means of characterizing machinability. It is stated that there is a need for prospective studies in this area (Blais et al., 2001). Šalak et al. (2006) have successfully performed the face turning technique at constant cutting conditions for evaluating machinability of Fe-C and Distaloy type PM steels with different compositions, and they evaluated the results with common processing criteria. Blais et al. (2001) performed the drilling operations of sintered steel in order to investigate the influence of additions such as different contents of copper, carbon, and MnS on the tool wear. Capus (2013) explained the machinability of austenitic stainless steel PM parts using turning and drilling operations and examined the effect of different material compositions on tool life. The Turning test was carried out for high-performance PM steels by M'Saoubi et al. (2014) and Robert-Perron et al. (2007-b). It was concluded in both studies that the levels of machining parameters can be optimized to prevent tool wear and improve surface roughness. It was also stated that the set cutting parameters had a significant effect on the result of the machining process. When the literature is examined, it is seen that most researchers have investigated the effect free machining additives on the machinability of the various PM materials, such as ASC 100.29 powder Hamiuddin and Murtaza (2001), premixes iron powder Capus (1981), Fe-2Ni-0.6C powder Obikawa et al. (2012), Distaloy SA and PNC45 powders Engström (1983), $\mathrm{Fe}-2 \mathrm{Cu}-0.8 \mathrm{C}$ powders Obikawa et al. (2018). Alizadeh (2008) investigated the effect of alloying elements and processing routes on the machining behavior of iron based PM components and discussed the effect of porosity in terms of deformation cutting theories. Robert-Perron et al. (2007-b) studied the machining behavior of green PM components during drilling and stated the 
necessity of optimization of the cutting parameters. Desbiens et al. (2012) characterized the green machining effect on the tensile and fatigue strength of sinter-hardened steel components. Czampa et al. (2013) studied the machinability performance of the sintered parts comprising $\mathrm{Fe}-\mathrm{Cu}-\mathrm{C}$ by drilling tests. Agapiou et al. (1988) presented the influence of porosity for machining of PM 304L austenitic stainless steel. Zurecki et al. (2003) characterized the finish turning of hardened PM steels by investigating tool life, cutting force, and surface integrity. Armarego et al. (2001) made a review on the machining performance and modelling the cutting action of FC-0208 sintered materials. Ozçatalbaş (2014) put forth an experimental study to determine machinability properties of PM 2000 alloy with coarse grains. Jin et al. (2011) studied the effect of cutting speed on the surface quality for PM nickel-based super alloy. Andersson and Berg (2005) studied the machinability of the chromium alloyed sinter hardened material by turning tests and found that the machinability is influenced by the choice of insert tool material grade, additives, and cutting conditions.

Distaloy is today the most widely used raw material worldwide for the production of complex, precise, high strength PM machine parts. Low alloy steel powder, which is commercially known as Distaloy AB, and whose predominant producer is still Höganäs, is a partially prealloyed iron powder containing copper, nickel, and molybdenum, and copper promotes hardenability in PM parts (Lindskog, 2013). The use of PM structural parts is growing in part due to the use of the sinter hardening process, which utilizes high performance materials in combination with an accelerated post sintering cooling rate. Interest in sinter-hardening has grown because it offers good manufacturing economy by providing a one step process and a unique combination of strength, toughness, and hardness ( Höganäs, 2004-b; Lindskog, 2013). It is important to work with this group of powder due to the wide range of use and all these superior properties. There is a growing need to solve machining behavior with increasing demand for this PM steel. Consequently, the machining of this material is an emerging topic for both science and industry. There is no published data regarding machinability studies of low alloy PM steels using different cutting parameters by turning method. The aim of this study is to fill the gap in the literature regarding this subject. The main focus of the investigations presented in this study is on characterizing the effects of different cutting parameters on the machinability of Cu-Ni-Mo based low alloyed sinter-hardened steels. The machinability was handled in terms of chip formation, surface quality, cutting forces, and tool life.

\section{EXPERIMENTAL PROCEDURE MATERIAL}

The workpieces were based on prealloyed $\mathrm{Cu}-\mathrm{Ni}-\mathrm{Mo}$, water atomized low-alloyed Distaloy AB steel powder, which is a registered trademark of Höganäs Company, Sweden. The chemical compositions of the powder used are given in Table 1. Zinc stearate was added to the powder premix to add lubricant during pressing, and fine graphite (UF4) as carbon was added to improve mechanical properties. The average particle size of powder was $110 \mu \mathrm{m}$ with irregular shapes. Each compact was pressed into hollow cylinder dies of $20 \mathrm{~mm}$ height, $10 \mathrm{~mm}$ inner diameter and 20 mm outer diameter.

Table 1. The chemical composition of the powder (wt.\%).

\begin{tabular}{|c|c|c|c|c|c|c|}
\hline Base Powder & $\mathbf{C u}$ & $\mathbf{N i}$ & $\mathbf{M o}$ & $\mathbf{C}$ & Lub. & $\mathbf{F e}$ \\
\hline Distaloy AB & 1.5 & 4.0 & 0.5 & 0.6 & 0.8 & Bal. \\
\hline
\end{tabular}

The specimens were sintered at $1130{ }^{\circ} \mathrm{C}$ for $30 \mathrm{~min}$. in an industrial continuous pusher furnace under $25 \% \mathrm{~N}_{2}-75 \%$ $\mathrm{H}_{2}$ (cracked ammonia) atmosphere. After the sintering step, the specimens were cooled with a cooling rate of $0.5^{\circ} \mathrm{C} /$ sec, which corresponds to normal sintering cycle, and with higher cooling rates of $2{ }^{\circ} \mathrm{C} / \mathrm{sec}$ for sinter hardening process. Microstructural characterization and mechanical tests of as-sintered and sinter-hardened specimens were performed. The specimens were grinded and polished in cloths with alumina and pure water and then etched in 3\% Nital solution for optical examination. Olympus PME3 optical microscope was used for microstructural examination. Rockwell B 
(HRB) scale was used to measure the macrohardness of the specimens in Zwick hardness testing machine. Three different locations were selected on the surface of the specimens, and the average of those values was used as the hardness measure of samples. Compression test of the specimens was investigated at room temperature using the Zwick-Roell Z250 materials-testing machine fitted with a $250 \mathrm{kN}$ load cell operating at the displacement control mode, with a strain rate of $0.05 \mathrm{~mm} \mathrm{sec}^{-1}$. The microstructures of as-sintered and sinter-hardened with cooling rates of $2{ }^{\circ} \mathrm{C} / \mathrm{sec}$ are shown in Figure 1. The as-sintered specimens consisted of ferrite $(\mathrm{F})$, pearlite $(\mathrm{P})$, austenite $(\mathrm{A})$, and a small amount of bainite (B) phases. The microstructural images of the sintered specimens showed that copper was accumulated in the grain boundaries as a result of sintering. The micropores (MP) formed in the specimens due to the melting of copper particles at the sintering temperature $1130{ }^{\circ} \mathrm{C}$. Martensite $(\mathrm{M})$ phase is not observed in the microstructure of the assintered specimens due to furnace cooling step of sintering cycle. The sinter hardening process enhanced the mechanical properties of the specimens, as a consequence of microstructure strengthening. The amount of pearlite and bainite phases increased, and the martensite phase formed in the structure, as a result of high cooling rate. In the micrograph, bright regions are martensite, darker regions are bainite plus pearlite, brown regions are austenite, and black regions are micropores between the steel particles. Phases indicated by arrows in the microstructures were confirmed using the microstructure of Distaloy AB steel given in the literature (Höganäs, 2004-c).
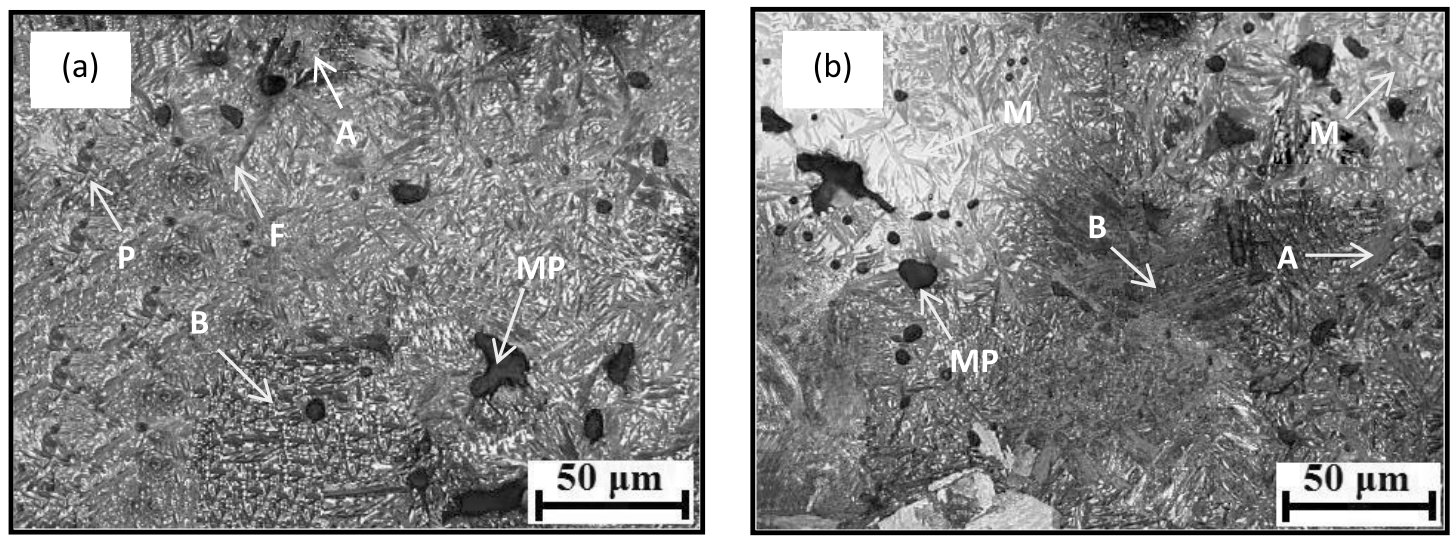

Figure 1. Microstructure of workpieces: (a) as-sintered and (b) sinter-hardened with cooling rate of $2{ }^{\circ} \mathrm{C} / \mathrm{sec}$.

The sintered density determined from measurements of weight and dimensions of the workpieces was close to 7.1 $\mathrm{g} / \mathrm{cm}^{3}$ for all materials. Previous work has indicated that exceptional mechanical properties and high apparent hardness values can be achieved by sinter hardening in a high temperature furnace with standard cooling (Bekoz, 2013). This paper addresses the influence of different cutting parameters on the machinability of sinter hardenable PM steels. Mechanical properties were assessed based on the compression test results. The macrohardness and the compressive yield strength values of as-sintered and sinter-hardened specimens are given in Table 2. Compressive yield strength and macrohardness values of the sinter-hardened specimens increased with the increase in cooling rate after sintering. As a result of high cooling rate, the amount of pearlite and bainite phases increased, and the martensite phase formed in the structure. This is the reason for the increase in the mechanical properties of sinter-hardened specimens. Increase in the compressive yield stress value of the specimen with the cooling rate of $2{ }^{\circ} \mathrm{C} / \mathrm{sec}$ was about $21 \%$ for Distaloy AB. The increase in macrohardness value achieved with sinter hardening was about $24 \%$.

Table 2. The macrohardness and compressive yield strength of as-sintered and sinter-hardened specimens.

\begin{tabular}{|c|c|c|}
\hline $\begin{array}{c}\text { Mechanical properties } \\
\text { of the specimens }\end{array}$ & $\begin{array}{c}\text { Macrohardness } \\
\text { (HRB) }\end{array}$ & $\begin{array}{c}\text { Compressive yield } \\
\text { strength (MPa) }\end{array}$ \\
\hline As-sintered & $89 \pm 6$ & $385 \pm 25$ \\
\hline Sinter-hardened & $110 \pm 4$ & $465 \pm 38$ \\
\hline
\end{tabular}




\section{MACHINABILITY TESTS}

As stated in the introduction, turning is the most appropriate operation to be applied to the PM parts. Machinability was assessed by single-point turning on a CNC lathe centre having a variable spindle speed $3000 \mathrm{rpm}$ rated at $30 \mathrm{~kW}$ using orthogonal cutting. A polycrystalline based cutting insert whose commercial name is $P C B N$ Seco grade CBN200 was used during the face turning of the samples. The rake angle $\gamma_{0}$ was $0^{\circ}$, flank angle $\alpha$ was $6^{\circ}$, and the cutting edge angel $\kappa_{\gamma}$ was $90^{\circ}$. The inserts, from Seco Tool Company, were clamped on the same tool holder used for the tool life tests. All machinability tests were conducted in a dry condition without any coolant. Cutting speeds were determined as 50,150 , and $250 \mathrm{~m} / \mathrm{min}$, feed rates as $0.05,0.1$, and $0.15 \mathrm{~mm} / \mathrm{rev}$, and cutting depths as $0.2,0.4$, and $0.6 \mathrm{~mm}$. The machinability tests that are most frequently found in the PM literature are tool wear, cutting force, chip formation, and surface roughness tests (Armarego et al., 2001; Blais et al., 200; Hamiuddin and Murtaza, 2001; Jakubéczyová and Fáberová, 2002; Klink et al., 2011; Lalbondre et al., 2013; Selvakumar et al., 2012; Šalak et al., 2005; Šalak et al. 2006; Trent and Wright, 2000). All mentioned machinability tests were performed in this study. The results were evaluated in detail with different cutting parameters. Surface roughness of machined specimens was measured by a Surftest 210 type Mitutoyo surface profilometer (Mitutoyo, Japan) with $5 \mu \mathrm{m}$ tip radius, and measurements were carried out using the average of the five measurements by the feed direction. The surface roughness arithmetic average of the profile $(\mathrm{Ra})$ was determined by comparing all the peaks and valleys with the mean line. Surface profile of every measurement was also produced by means of a software (Surface Roughness Tester SJ-210/310/410 program), which was interfaced to the instrument. The characterization of the surface finish of machined specimens and inserts was performed by SEM (Quanta FEG450 model) at different magnifications. Chip formation mechanisms were examined by a Nikon SMZ800 model stereo microscope. Turning forces were measured by using 9129 type Kistler Lathe Dynamometer (Kistler, Switzerland) with the rate of $1000 \mathrm{~Hz}$.

\section{RESULTS AND DISCUSSIONS SURFACE QUALITY}

Surface roughness of the machined surface is the most frequently measured quality characteristic. Surface roughness plays a significant role in service life and parts measurement of part accuracy affected by many factors (Obikawa et al., 2012). The important parameters affecting the surface roughness are the feed rate, cutting speed, and depth of cut (Saini et al., 2012). Surface roughness expressed as $\mathrm{Ra}$ is the arithmetic mean of the absolute values deviation from mean line and profile and is characterized according to the mentioned cutting parameters. Variation of surface roughness values of turned PM steel in various cutting parameters was shown in Figure 2.

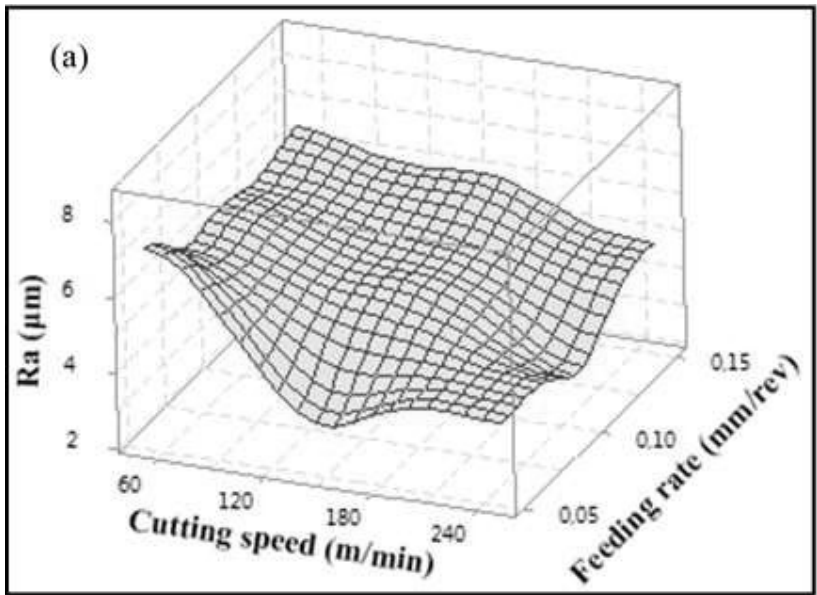



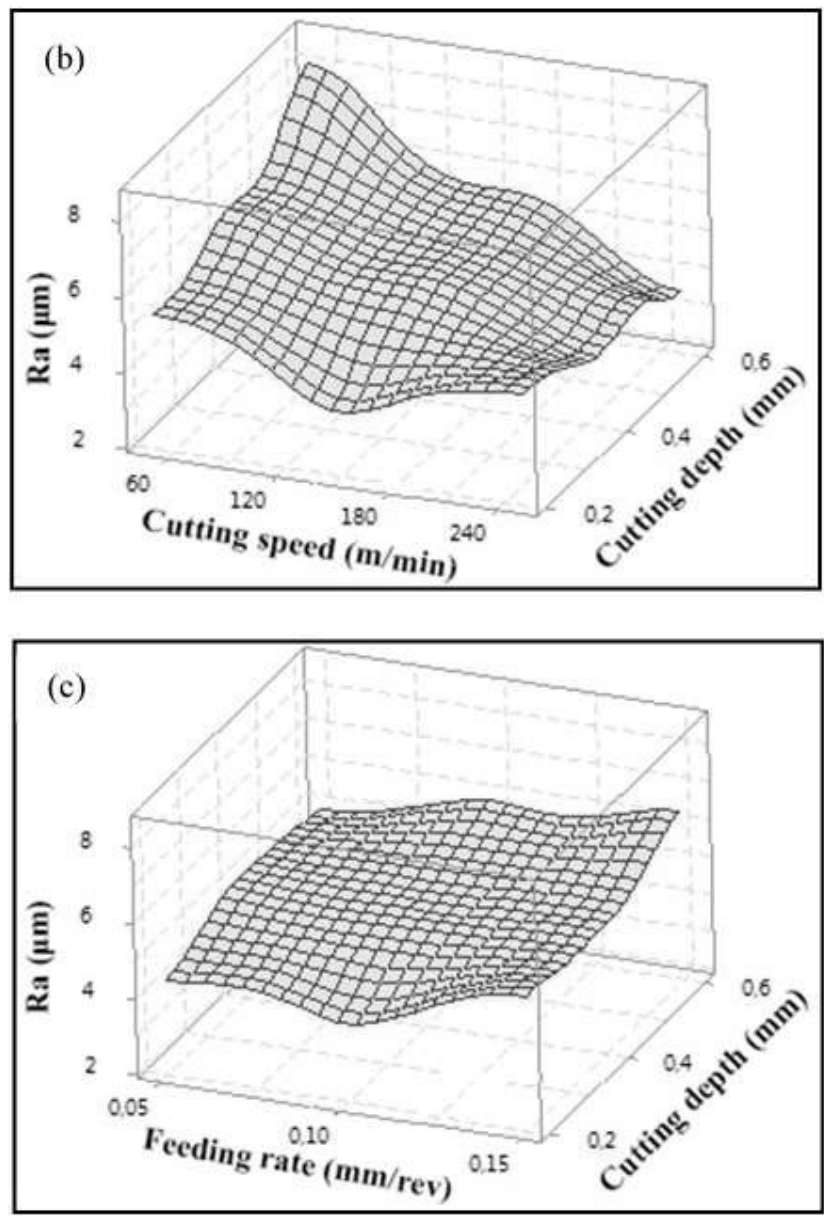

Figure 2. Variation of surface roughness on the machined surface as a function of different cutting parameters:

(a) cutting speed and feed rate, (b) cutting speed and depth of cut, and (c) feed rate and depth of cut.

It is seen from Figures 2 (a) and (b) that the cutting speed has a significant effect on the surface roughness. Surface roughness value decreased with the increase in the cutting speed. In particular, about $40 \%$ reduction in the Ra value was observed when the amount of cutting speed increased from $50 \mathrm{~m} / \mathrm{min}$ to $250 \mathrm{~m} / \mathrm{min}$. The surface roughness is sensitive to changes in feed rate and depth of cut. Ra values increased with the increase in feed rate and depth of cut. As the feed rate increased from $0.05 \mathrm{~mm} / \mathrm{rev}$ to $0.15 \mathrm{~mm} / \mathrm{rev}$, Ra increased by $20 \%$. In the same way, Ra increased by $24 \%$ when the cutting depth increased from $0.2 \mathrm{~mm}$ to $0.6 \mathrm{~mm}$. The combination of parameters between low depth of cut and feed rate with high cutting speed is suitable for minimum surface roughness. Consequently, as the cutting speed increased, the cutting plastic deformation area tended to decrease. This could positively affect surface roughness at the higher cutting speed, while other cutting parameters are fixed. The results obtained are in accordance with the literature (Ozcatalbas, 2003-a). Lalbondre et al. (2013) stated that the surface roughness values are in a narrow band and a have relatively lower Ra value at higher speeds. They explained that the temperature at tool-workpiece-chip region is high due to the increased speed. The cutting edge quickly loses its sharpness in roundness, and this leads to better surface quality. M'Saoubi et al. (2014) reported that the higher cutting speeds and increased crater depth affect surface quality positively. According to Chambers (1996), the most major factor explaining the surface quality is the formation of built-up edge. It was explained in his research that it is possible to observe high Ra at low cutting rate due to the height of built-up edge reflected under the cutting edge. Similar descriptions were expressed by Ozcatalbas (2003-b) and Jin et al. (2011) regarding PM materials. As a result of experimental studies, the surface finish is sensitive 
to changes in all cutting parameters used in the study. The increase of cutting speed has a positive effect on surface finish; in other words, it causes a decrease in surface roughness values. Increased feed rate and cutting depth adversely affect surface quality. The combination of low feed rate and cutting depth at high cutting speeds is a suitable parameter for minimum surface roughness. Visual inspection of the machined surfaces is required to better understand the effects of the cutting parameters on the surface quality. Figures 3-5 illustrate the SEM images of the machined surface with different cutting parameters at different magnifications. The SEM images with $0.4 \mathrm{~mm}$ depth of cut and $0.10 \mathrm{~mm} / \mathrm{rev}$ feed rate at varying cutting speeds, the SEM images with $250 \mathrm{~m} / \mathrm{min}$ cutting speed and $0.6 \mathrm{~mm}$ depth of cut at varying feed rates, and the SEM images with $150 \mathrm{~m} / \mathrm{min}$ cutting speed and $0.15 \mathrm{~mm} / \mathrm{rev}$ feed rate at varying cutting depths are given in Figures 3-5, respectively.
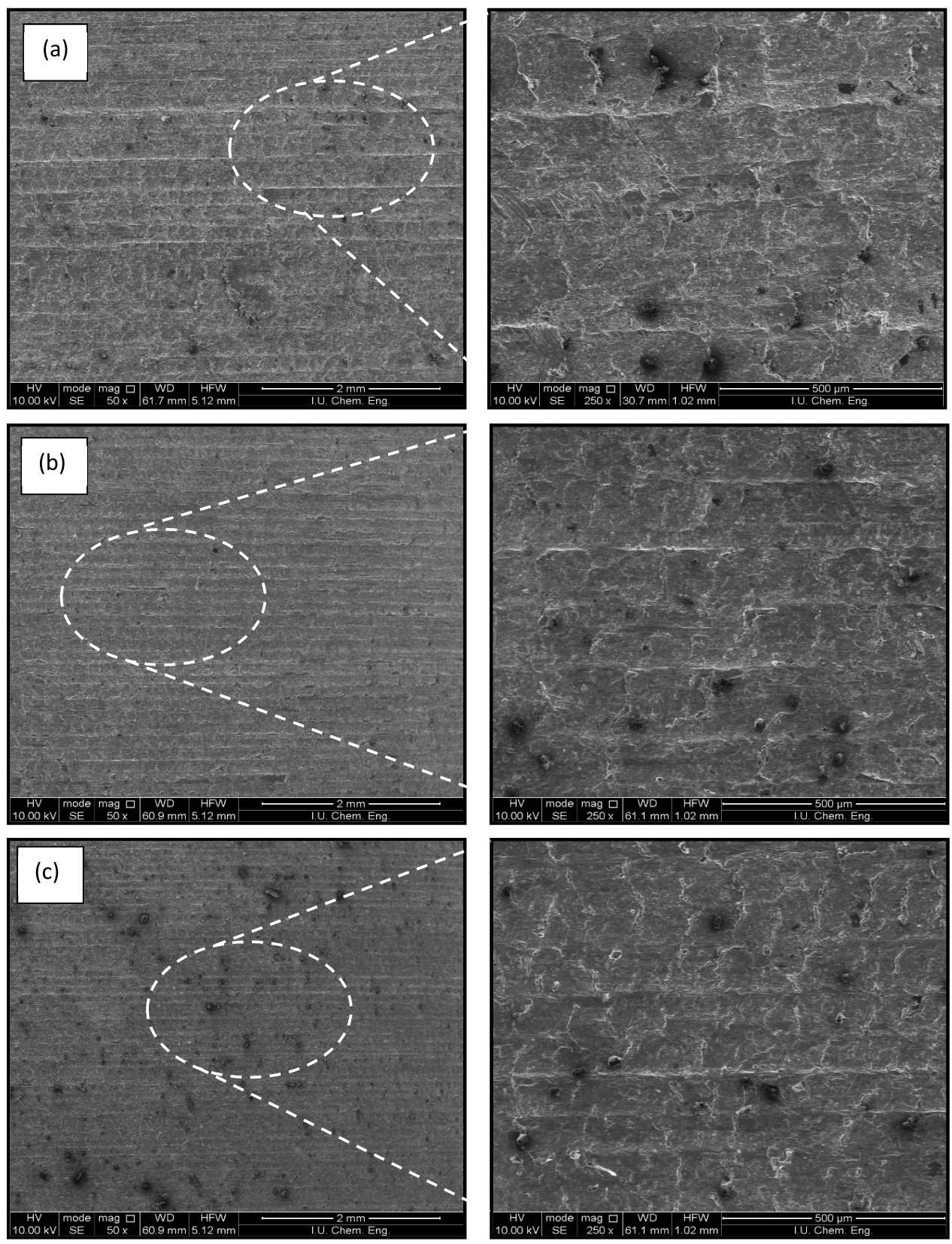

Figure 3. SEM images of machined surface at different cutting speeds: (a) $50 \mathrm{~m} / \mathrm{min}$, (b) $150 \mathrm{~m} / \mathrm{min}$, and (c) $250 \mathrm{~m} / \mathrm{min}$. 

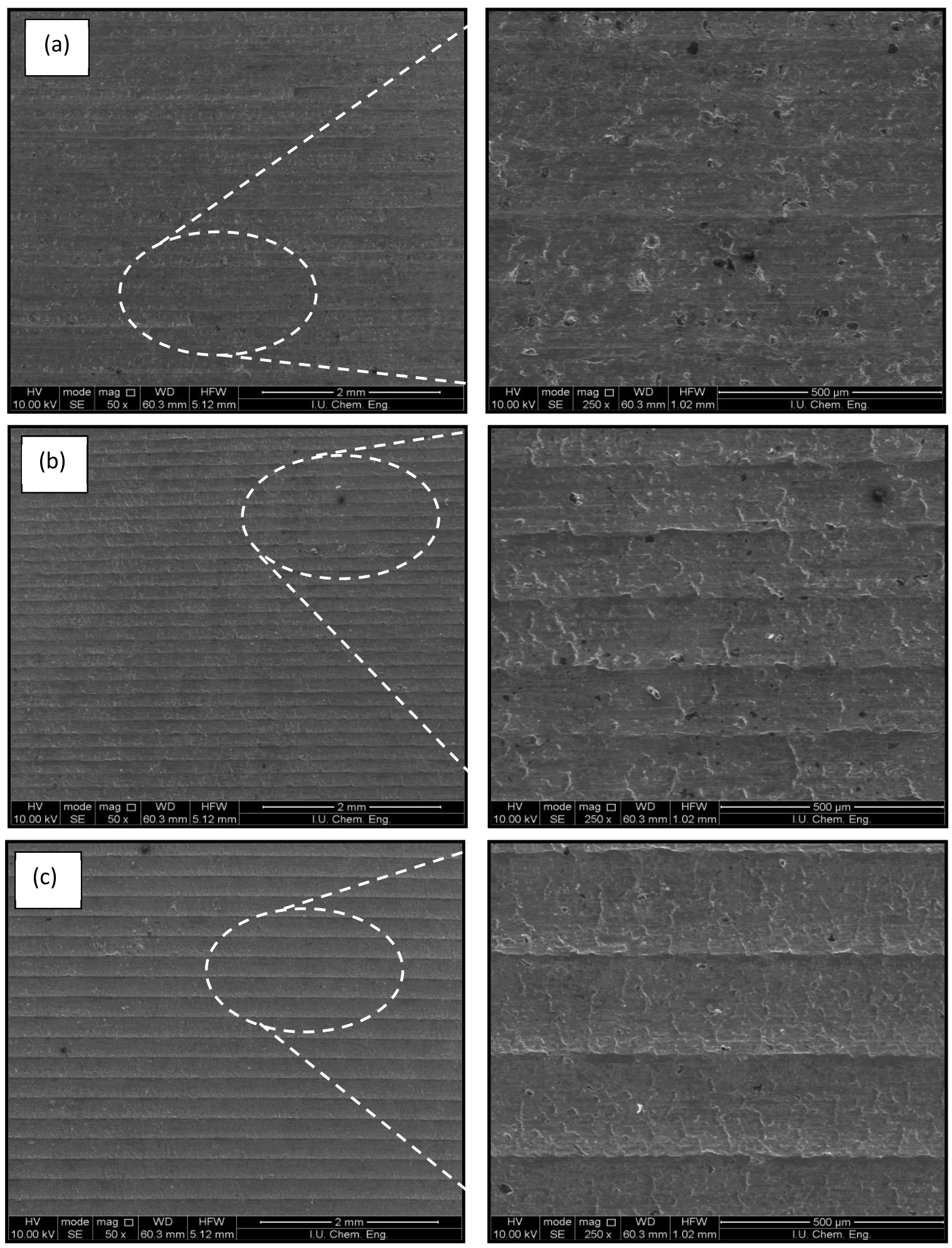

Figure 4. SEM images of machined surface at different feed rates: (a) $0.05 \mathrm{~mm} / \mathrm{rev}$, (b) $0.1 \mathrm{~mm} / \mathrm{rev}$, and (c) $0.15 \mathrm{~mm} / \mathrm{rev}$. 

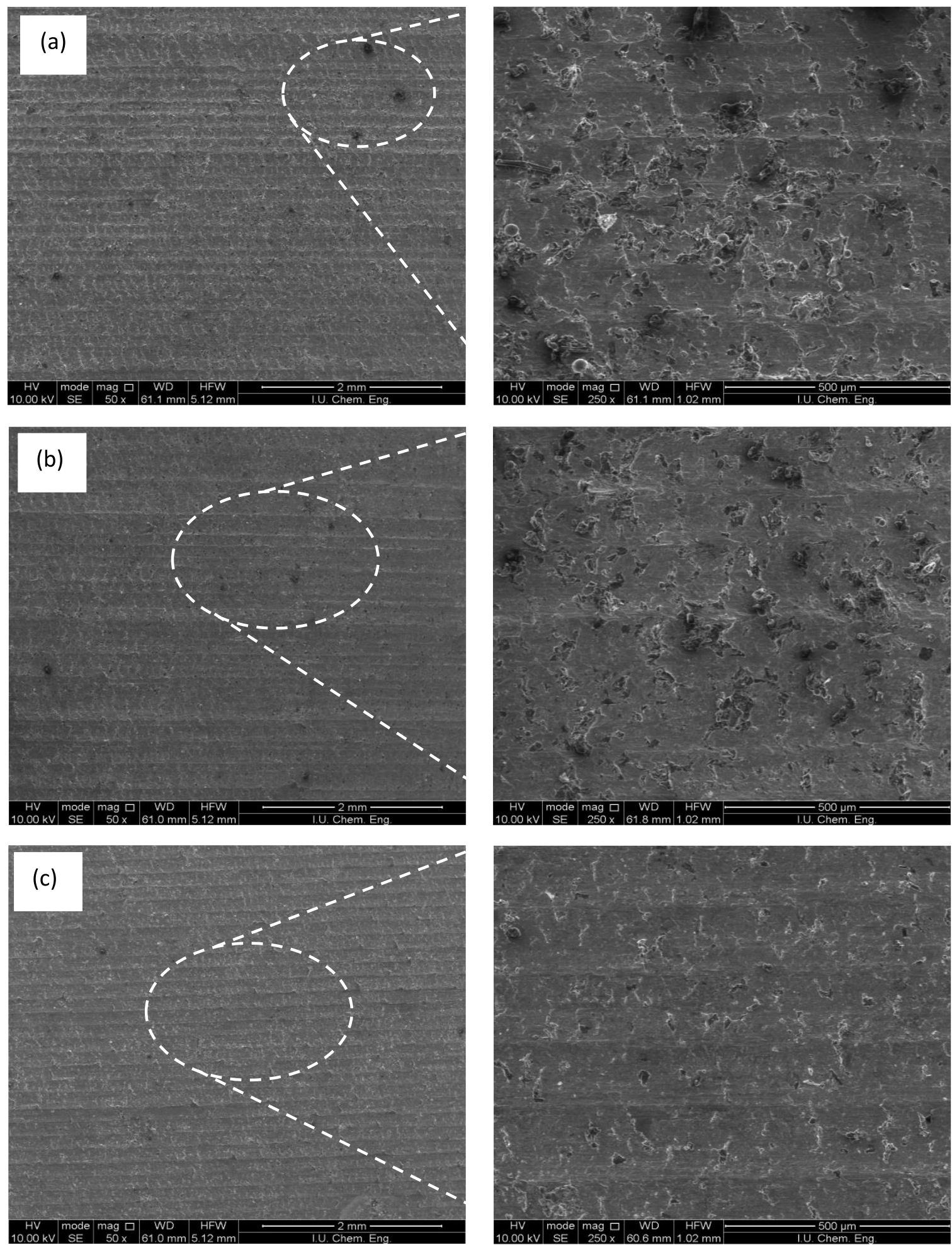

Figure 5. SEM images of machined surface at different depth of cuts: (a) $0.2 \mathrm{~mm}$, (b) $0.4 \mathrm{~mm}$, and (c) $0.6 \mathrm{~mm}$. 
Figures 3-5 show the significant difference in surface quality of workpiece, which was subjected to turning process by different cutting parameters. Microcracks were not observed on the machined surfaces. In accordance with SEM image, it is clear that the surface lines are parallel to each other and almost equally spaced. The surface of workpieces showed uniform grooves at regular intervals across the surface of the PM parts, and no adverse features were evident. In the cutting conditions used in the study, material flow and smearing were not observed. The oxides in the form of black spots on the surface were detected by SEM/EDS due to the porosity of the structure after machining. The surface roughness decreased with the increase in the cutting speeds. The surface quality of the machined parts at $250 \mathrm{~m} / \mathrm{min}$ cutting speed was better than lower cutting speeds as shown in Figure 3. The wear marks on the machined surface can be minimized by increasing the cutting speed. The feed rate and depth of cut have a similar effect on surface roughness. The feed pattern is less distinct, and this also could be seen at Ra values. As seen in Figures 4 and 5, the traces on the machined surface become more obvious with the increase in the feed rate and cutting depth. According to the results, the fact that machined surfaces were smoother by the increase in cutting speed and decrease in feed rate and cutting depth is thought to be a consequence of less smearing during machining. Özçatalbaş (2014) also showed a similar interaction between cutting parameters and the surface roughness. Gökkaya (2010), Ozcatalbas (2003-a), and Ozcatalbas (2003-b) reported that the formation of small size built-up edge reduces the machining errors on the machined surface at high cutting speeds. The machinability is clearly superior for the machined surface with high cutting speed compared to the machined surface with low cutting speed in respect of surface. Evaluation of the SEM images is compatible with the surface roughness results given above. The results of many studies on machinability of PM parts have verified the influence of the cutting parameters on the roughness (Bhushan et al., 2010; Chambers, 1996; Gökkaya, 2010; Ozcatalbas, 2003-a; Ozcatalbas, 2003-b; Saini et al., 2012).

\section{CHIP FORMATION}

Chip formation in a continuous chip removal process is very important in terms of workpiece quality and cutting tool life. The chip sizes formed in turning of PM sinter-hardened steels are shorter depending on workpiece material, cutting tool, cutting fluid, machine characteristics, and cutting parameters (Alizadeh, 2008). The main factors that affect the chip flow are the type of the tool and the friction between the chip-tool and workpiece (Robert-Perron et al., 2007-b). The effect of porosity of PM part on the chip formation and chip continuity has been expressed in many studies (Robert-Perron et al., 2007-b, Robert-Perron et al., 2007-c). Chip formation is indispensable in understanding the machining performance and providing basic information about cutting process. Figures 6-8 show the chips that were formed in turning of the sintered steels at different cutting speeds, feed rates, and depth of cuts, respectively. Figures 6-8 indicate the macrophotographs of the chips that formed in machining at different parameters, respectively: chips formed by $0.4 \mathrm{~mm}$ depth of cut and $0.10 \mathrm{~mm} / \mathrm{rev}$ feed rate at varying cutting speeds; chips formed by $250 \mathrm{~m} / \mathrm{min}$ cutting speed and $0.6 \mathrm{~mm}$ depth of cut, at varying feed rates; chips formed by $150 \mathrm{~m} / \mathrm{min}$ cutting speed and $0.15 \mathrm{~mm} /$ rev feed rate, at varying cutting depths. 

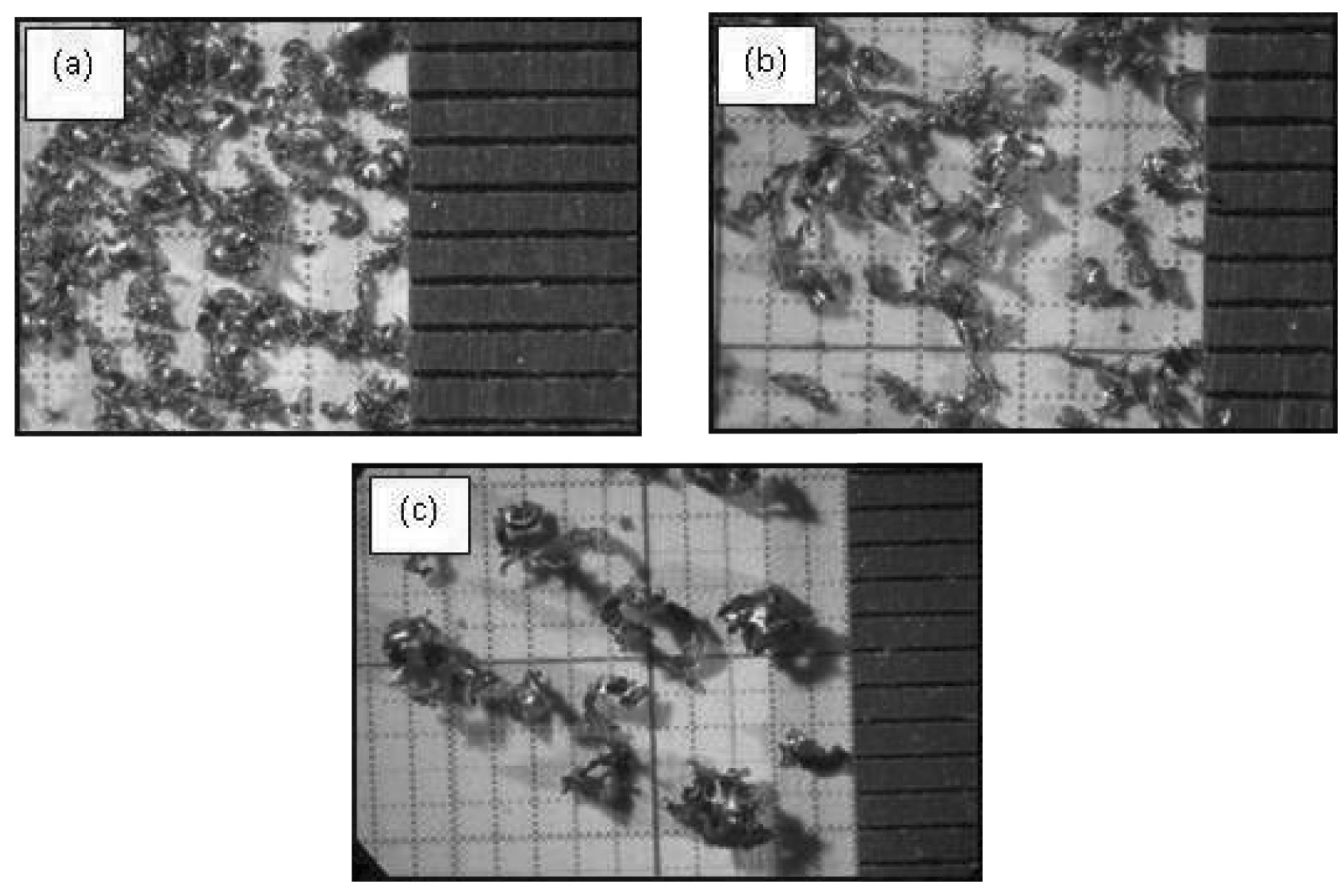

Figure 6. Chip formed in turning of machined surface at different cutting speeds: (a) $50 \mathrm{~m} / \mathrm{min}$, (b) $150 \mathrm{~m} / \mathrm{min}$, and (c) $250 \mathrm{~m} / \mathrm{min}$.
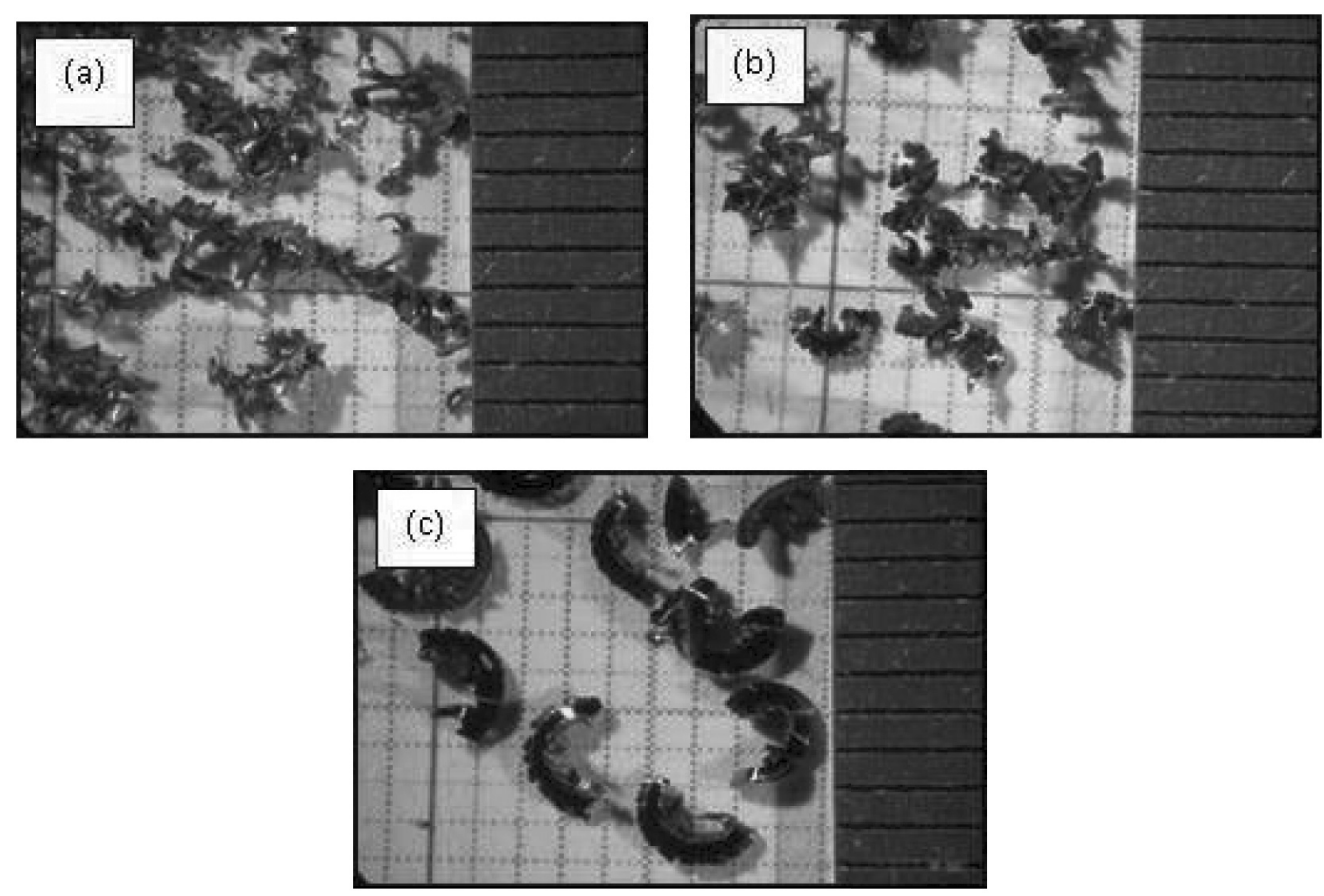

Figure 7. Chip formed in turning of machined surface at different feed rates: (a) $0.05 \mathrm{~mm} / \mathrm{rev}$, (b) $0.1 \mathrm{~mm} / \mathrm{rev}$, and (c) $0.15 \mathrm{~mm} / \mathrm{rev}$. 

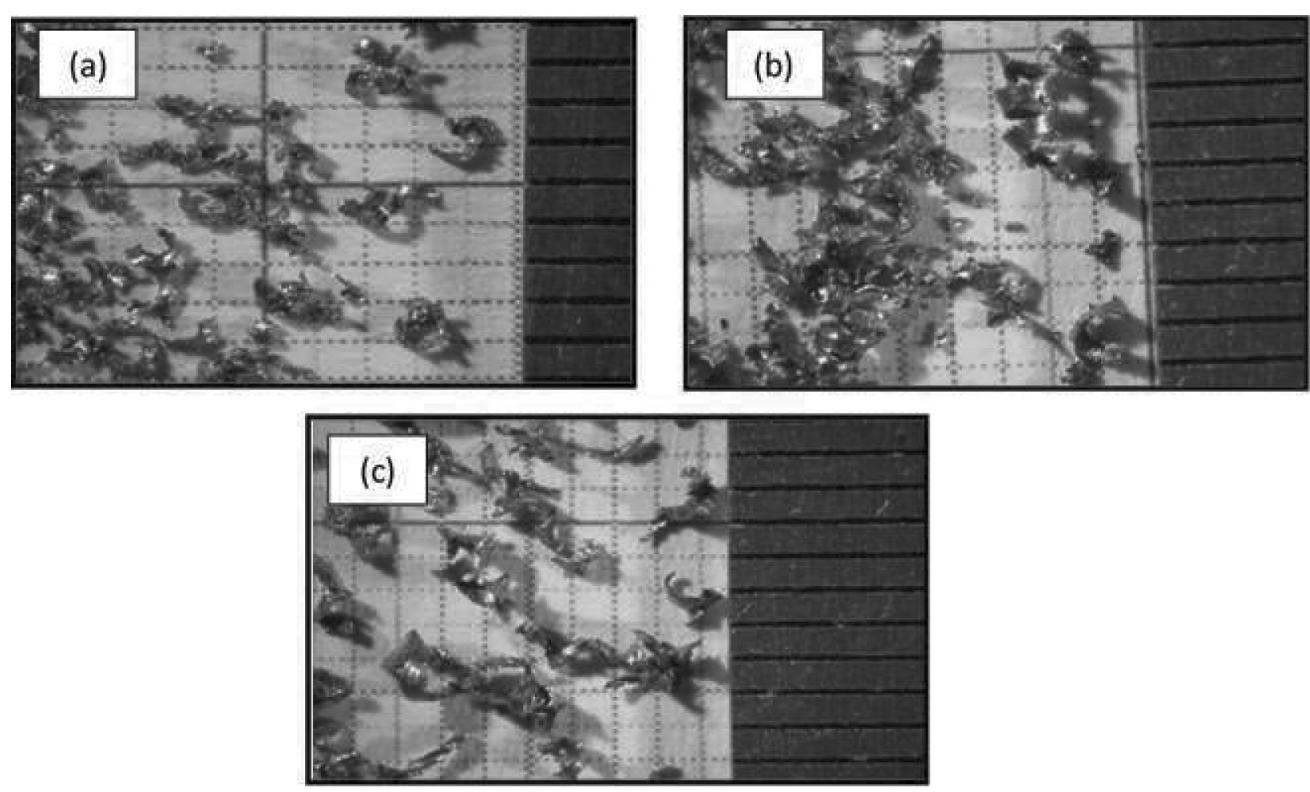

Figure 8. Chip formed in turning of machined surface at different depth of cuts: (a) $0.2 \mathrm{~mm}$, (b) $0.4 \mathrm{~mm}$, and (c) $0.6 \mathrm{~mm}$.

It is seen in Figures 6-8 that the chip length and thickness increase and the shape is slightly complicated with the increase in all parameters. The change in the chips formed in machining is a consequence of machining with different cutting parameters of tested material. As the cutting speed increased from $50 \mathrm{~m} / \mathrm{min}$ to $250 \mathrm{~m} / \mathrm{min}$, the chip size increased from about $1.5 \mathrm{~mm}$ to $2.5 \mathrm{~mm}$. The chip size increased from about $1 \mathrm{~mm}$ to $3 \mathrm{~mm}$ when the feed rate increased from $0.05 \mathrm{~mm} / \mathrm{rev}$ to $0.15 \mathrm{~mm} / \mathrm{rev}$. In the same way, the chip size increased from about $1 \mathrm{~mm}$ to $2 \mathrm{~mm}$ when the cutting depth increased from $0.2 \mathrm{~mm}$ to $0.6 \mathrm{~mm}$. The increase in chip size is explained in the literature by the increase in cutting speed and the decrease in the radius of the chip curvature. The contact length of the chip-tool is reduced by an increase in the cutting speed and causes a reduction in the effect of contact forces (Trent and Wright, 2000). A clear change was seen on the chip shape with the change of cutting parameters used in this study. Hwang and Chandrasekar (2011) reported that the observation of the tool-chip interface was shown due to the effect of the workpiece on the contact conditions, but not with the cutting parameters, such as cutting speed and feed rate. Short spiral shape and discontinuous type chips were formed without a significant deformation, and this means that the chip control was very good. During the experiment, the chips are brittle in powder form and produced discontinuous chips. Only plastic deformation of the metal occurs due to the very brittle structure of steel foam structures produced in this study when the cutting forces reach the yield strength of the material. Since there is no elastic deformation, the chip structure is in powder form (Heidari, 2018). The chips formed in machining PM materials are in powder form since the surfaces of the compacted pores are not cold-welded, although the cut occurs in a deformed layer (Šalak et al., 2006). The formation of the short chip is important in terms of operating safety of the operator, the safety of the cutting tool and the machine, the quality of the machined surface, and the ease of chip removal (Šalak et al., 2005). Some researchers reported that the comparatively short and thin chips produced in PM turning test are usually discontinuous (Šalak et al., 2005; Šalak et al., 2006; Trent and Wright, 2000). 1.5\% Cu content in the powder used in the study may be the cause of the brittle and discontinuous behavior of the chips. It has also been expressed in the literature that plastic deformation of the chips formed in machining is easy due to the effect of $\mathrm{Cu}$ (Höganäs, 2004-b). The formation of different chips may be the result of different size and shape of crater on the tool. This is also prevalent in other studies (Ebrahimi and Moshksar, 2009; Hwang and Chandrasekar, 2011; Lalbondre et al., 2013). Ozcatalbas (2003-a) claimed that the effect on friction between chip and tool with changing cutting parameters was caused a change in chip character. Hwang and Chandrasekar (2011) reported that the characterization of the chips that are formed during turning operation depends on the cutting conditions. The color of the chips darkened with the increase in cutting speed 
and feed rate, but the change in depth of cut did not affect the color. Ye et al. (2012) reported that the increase in the cutting speed would cause an increase in tool-chip contact temperature and a decrease in finished surface temperature. Colored chips evidence that the temperature in the cutting zone is high (Šalak et al., 2006).

\section{CUTTING FORCES}

Another feature used to describe the machinability is the measuring of the cutting forces, which is used in determining the tool and workpiece deflection. According to many researches, the cutting speed, feed rate, and depth of cut, cutting fluids, tool geometry, and strength of the workpiece affect the cutting forces ( Alizadeh, 2008; Gökkaya, 2010; Robert-Perron et al., 2005; Tambani et al., 2018). The resultant cutting force is usually divided into three components: axial force (Fx), cutting force (Fy), and feed force (Fz). The cutting force levels should be considered as the limit for the machine. These limits, in cutting and feed forces, can then be used in planning new operations and dimensions (Höganäs, 2004-a). Variations of axial force cutting force and feed force of turned workpiece in various cutting parameters were presented in Figures 9-11, respectively.
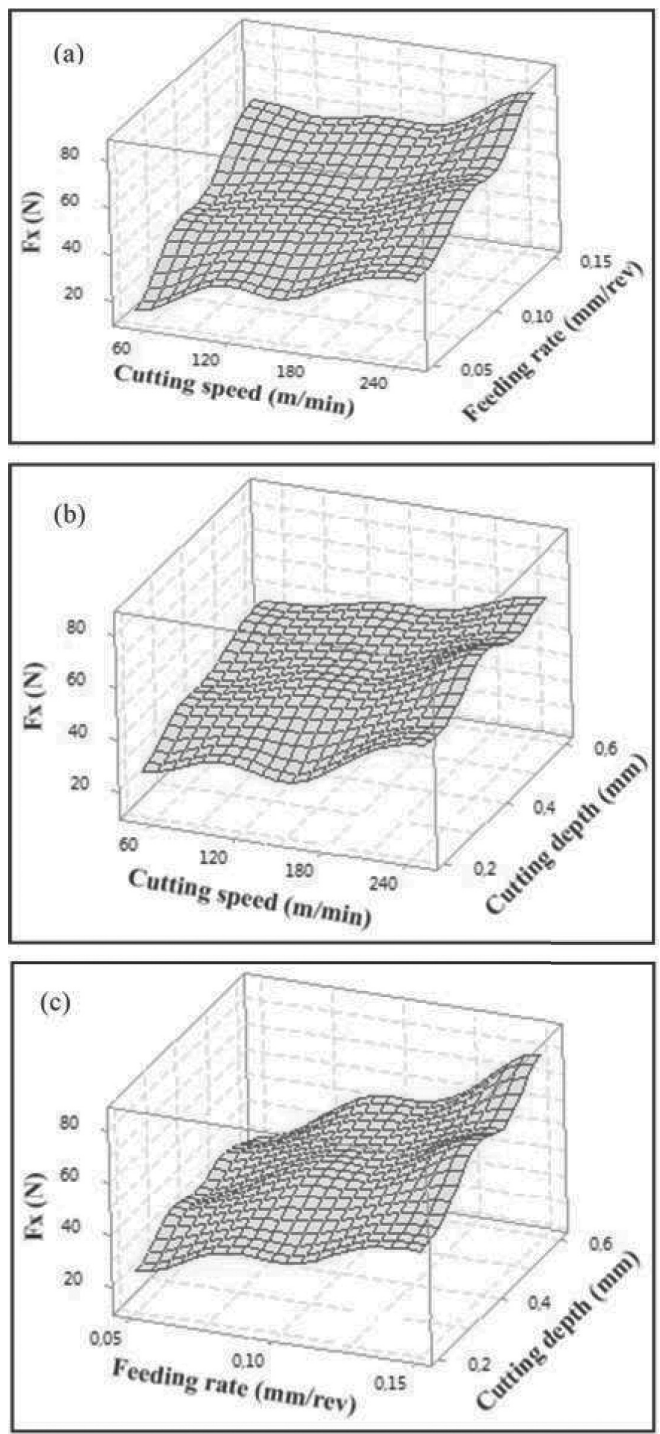

Figure 9. Effect on the axial force of different cutting parameters: (a) cutting speed and feed rate, (b) cutting speed and depth of cut, and (c) feed rate and depth of cut 

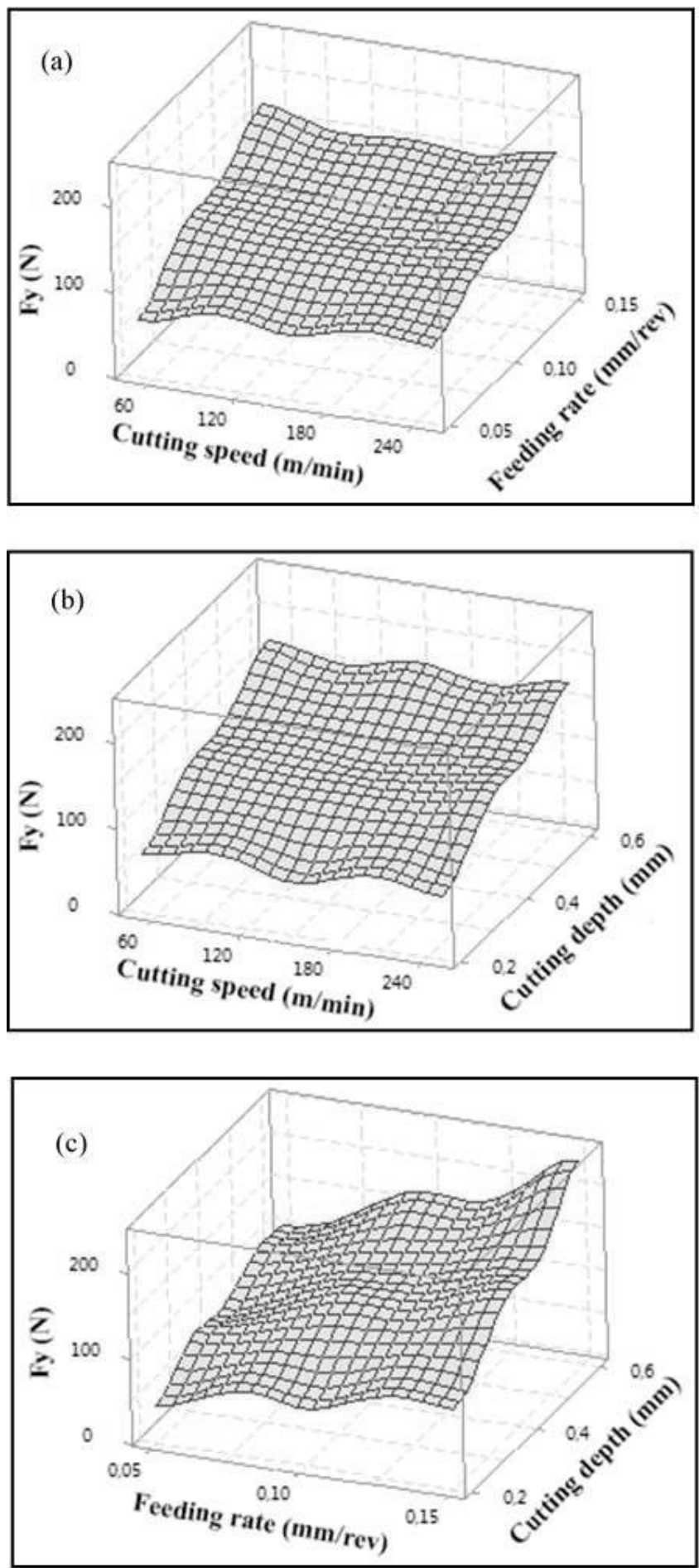

Figure 10. Effect on the cutting force of different cutting parameters: (a) cutting speed and feed rate, (b) cutting speed and depth of cut, and (c) feed rate and depth of cut. 

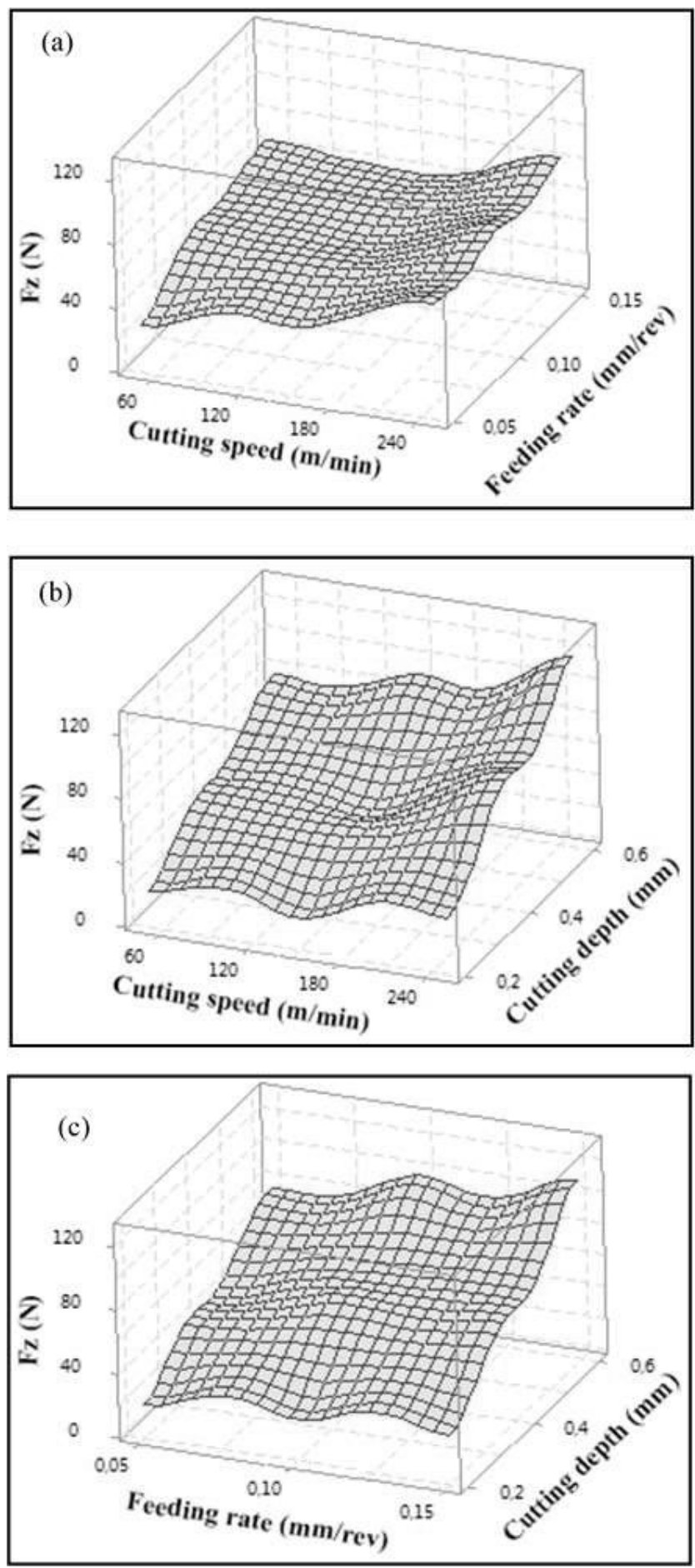

Figure 11. Effect on the feed force of different cutting parameters: (a) cutting speed and feed rate, (b) cutting speed and depth of cut, and (c) feed rate and depth of cut. 
It is seen in Figures 9-11 that the cutting speed, feed rate, and depth of cut influence all the forces mentioned above. The observed values directly show the effects of cutting parameters, because the cutting tool has not changed at the same time tool geometry. Both the axial and feed forces increased with the increase in cutting parameters. When the cutting speed, feed rate, and cutting depth increased from the lowest to the highest values, the axial forces increased by about $43 \%, 51 \%$, and $48 \%$, respectively. In the same way, the feed forces increased by about $55 \%, 66 \%$, and $24 \%$, respectively. The cutting force decreased by about $3 \mathrm{~N}$ with a reduction in the cutting speed from $50 \mathrm{~m} / \mathrm{min}$ to $150 \mathrm{~m} /$ min but increased by the increase in speed at $250 \mathrm{~m} / \mathrm{min}$. Together with increase in feed rate and cutting depth, the cutting force increased by about $62 \%$ and $40 \%$, respectively. Similar effects were also reported by Özçatalbaş (2014) and M'Saoubi et al. (2014) who studied the machinability of PM materials. Trent and Wright (2000) stated that the axial and feed forces were sensitive to changes in cutting parameters, tool wear, and workpiece properties much more than the main cutting force. Ozcatalbas (2003-b) reported that the changes of effect depend on the cutting speed. The differences in turning forces are greatest at the small feed rate. For this situation, it has been suggested in the literature that PM steels should be machined at the largest feed possible while still fulfilling the surface requirements (Trent and Wright, 2000). A difficult-to-machine material causes high cutting forces. In order to reduce them, the feed, the cutting, the depth of cut, and sometimes the cutting speed can be changed, which provides better productivity.

\section{TOOL LIFE}

Tool life is often influenced by the change of cutting speed and determined by tool wear in machining processes (Lalbondre et al., 2013). Tool wear can generally be classified as follows: adhesive wear, abrasive wear, fatigue wear, diffusion wear, etc. (Trent and Wright, 2000). The formations of built-up edge (BUE) and built-up layer (BUL) on the cutting insert are caused by excessive pressure and chip-tool interface temperature (Desaigues et al., 2016). Among the effects of tool wear, the most important one is flank wear (Blais et al., 2001). The only acceptable form of wear is flank wear because it can influence the surface roughness and accuracy (Blais and L'Espérance, 2002). The wear causes negative effects on the machined surface quality during the cutting operation. Therefore, it is important to take into account and evaluate this issue scientifically. In light of the literature reviewed, the cutting speed is selected as the main cutting parameter in tool operations due to its effect on the tool life-wear (Lalbondre et al., 2013). SEM images with regard to varying of cutting tool wear with the changes in cutting speeds are shown in Figure 12. The tool wear on the insert flank was determined by using a new insert. Figures 12 (a), (b), and (c) present the status of tool wear determined by the tool life. In addition to the increase in the cutting forces, the difficulties related to the dimensional tolerances and surface quality and increases in vibration and temperature are indicative of increased wear and the end of tool life. Tool life model operation includes cutting speed and flank wear that occur on the tool surface and are considered as parameters (Saini et al., 2012). The tool life is considered as a function of different cutting speeds in accordance with machining time. The criteria describing tool life may be interesting for a practical assessment of the effect of all factors, which are included the cutting process studied. Hence, the effect of different cutting speeds on the tool life is presented in Figure 13. 

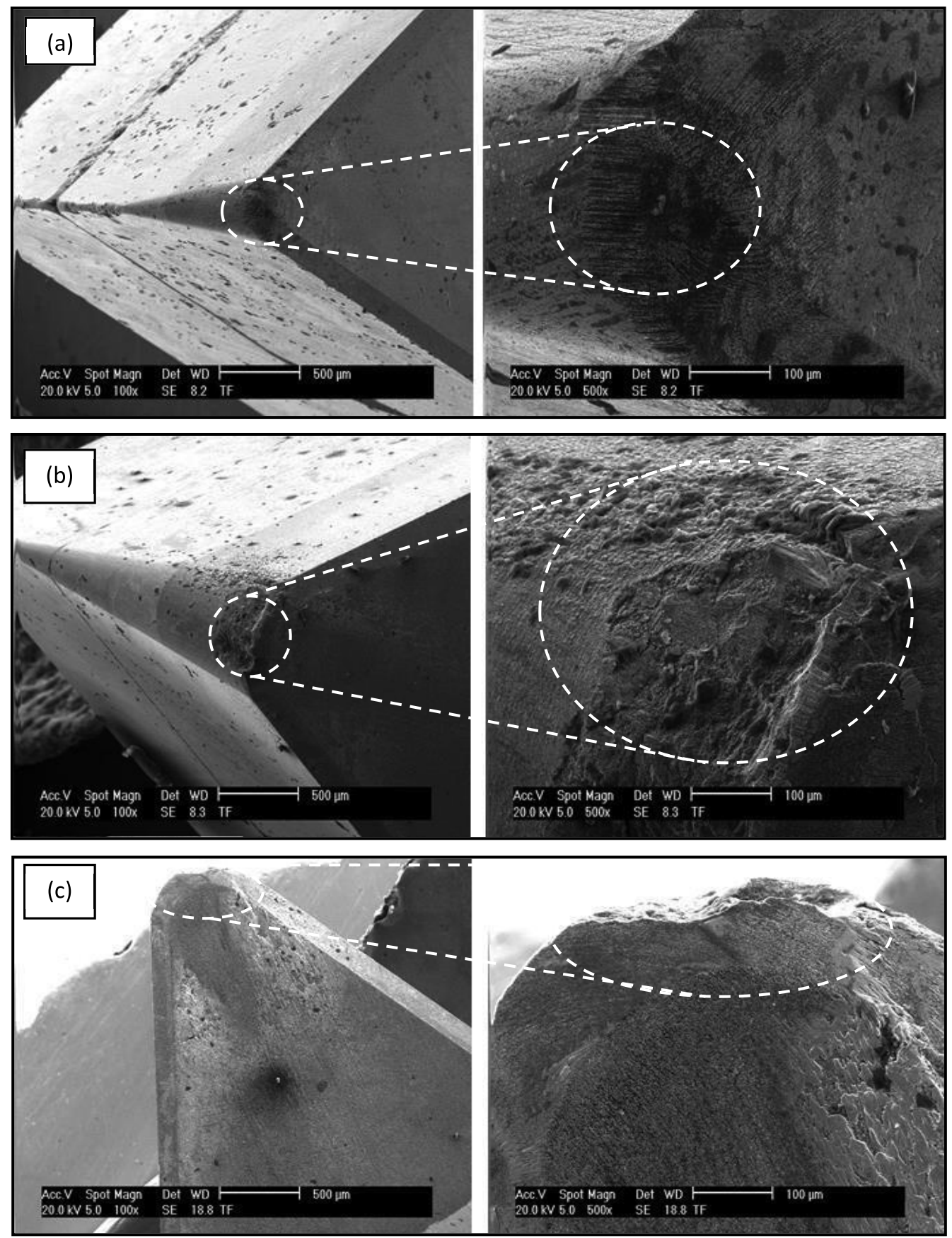

Figure 12. SEM images of tool wear at different cutting speeds: (a) $50 \mathrm{~m} / \mathrm{min}$, (b) $150 \mathrm{~m} / \mathrm{min}$, and (c) $250 \mathrm{~m} / \mathrm{min}$.

The tool wear was determined to be proportional to the chip length in the chip formation as stated in the previous section. The main wear mechanism is abrasive flank wear as shown clearly in Figure 12, especially at high cutting speed. It is mentioned in the literature that. abrasive flank wear is the dominant wear mechanism in metal cutting for PM materials (Lalbondre et al., 2013). M'Saoubi et al. (2014) reported that the increased cutting speed causes undesirable effects on the tool life as expected. Additionally, they determined the flank wear patterns and adhesion of the workpiece for all cutting tool inserts. The friction between the machined surface and the tool increases as the 
flank surface and the tool wears get larger. The increase in the force should be associated to that of flank wear surface. This is because the friction force increases as the real surface of contact increases. Changes in the cutting force can cause the cutting tool wear. Despite the chip volume at all cutting speeds, the tool wear increased with the increase in cutting speed. The high frequency of the forces caused the insert to wear without fatigue (Šalak et al., 2005). Traces of wear caused by fatigue are shown in Figure 12 (c). BUL formation were not detected on the flank face and rake face of the tool in this part of the study. BUL is frequently observed in machining ductile materials. The material used in the study is brittle, as it is understood from the chip form. The formation of BUE on the cutting tool can be seen very little adhering to the race face. It is known that the tool life is strongly affected by the cutting speed. This study verified this experimentally under a constant feed of $0.15 \mathrm{~mm} / \mathrm{rev}$ and depth of cut of $0.6 \mathrm{~mm}$ as shown in Figure 13. The experimental measurements have shown a linear variation of tool life, $T$ (in minutes) with respect to cutting speed, $V$ (in $\mathrm{m} / \mathrm{min}$.) as shown in Eq. [1]. The well-known Taylor's tool life relation has not been applicable for the $P C B N$ cutting tool and the sinter-hardened steel workpiece material combination.

$$
V+28.57 T=778.57 \quad \text { with } R^{2}=1
$$

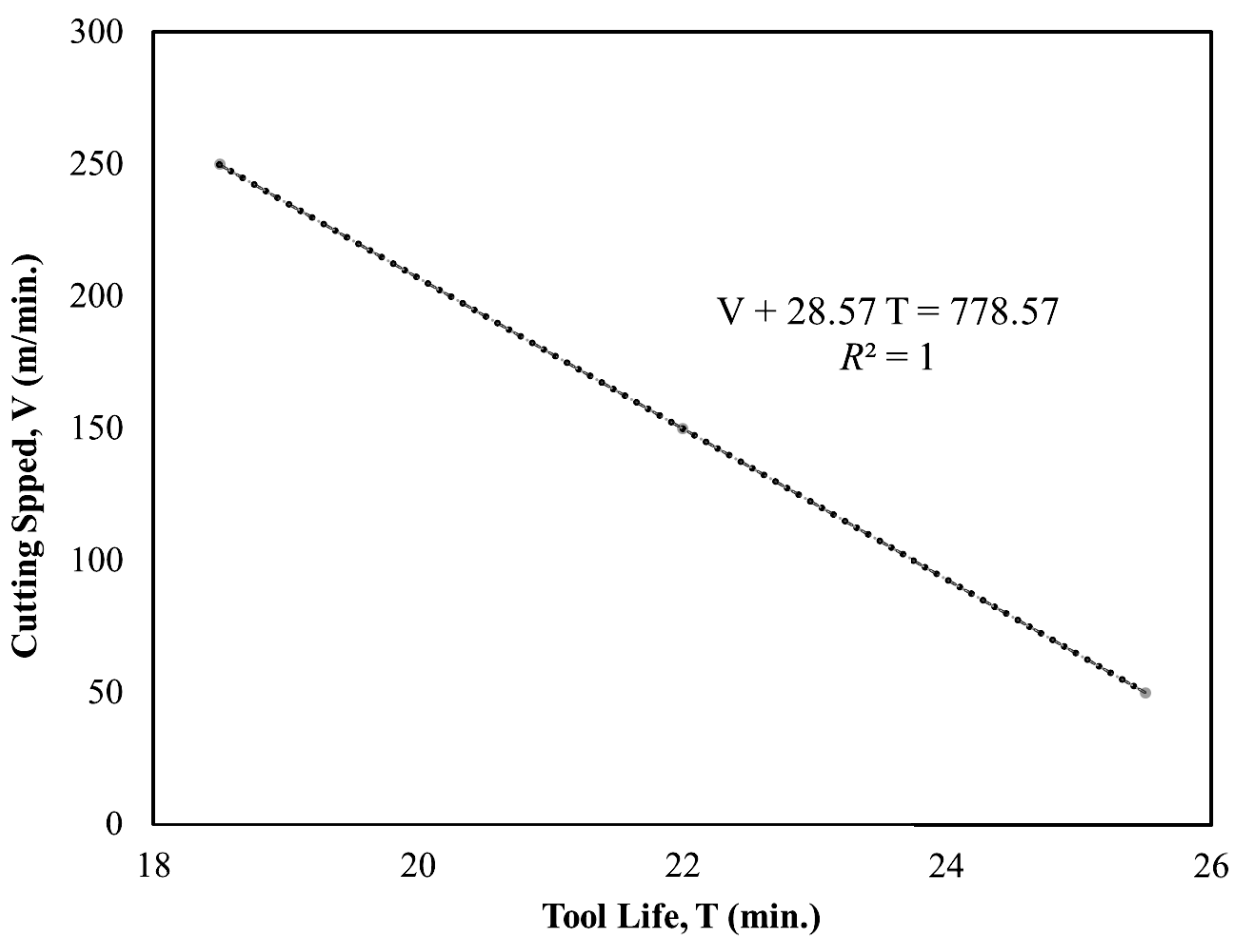

Figure 13. Effect on the tool life of different cutting speeds.

The tool wear increases by the increase in cutting speed until the chip breakage. The flank wear normally is accelerated due to notch formation resulting from this increase. These observations are compatible with the literature (Blais et al., 2001; Lalbondre et al., 2013; M'Saoubi et al., 2014). Grzesik and Nieslony (2000) reported that the amount of increased chip breaking causes tool wear due to unstable heat dissipation in the high speed chip formation area. The fact that alloyed PM compacts generally have a heterogeneous microstructure can create difficulties in processing technology and adversely affect tool life strength, especially for sinter hardenable steel components (Bekoz, 2013; Höganäs 2004-b). 


\section{CONCLUSIONS}

In this study, the machinability characterization of low alloyed PM sinter-hardened steel during turning operations was investigated by different cutting parameters. Machinability was discussed in terms of the chip formation, surface roughness, cutting forces, and tool wear. The main findings of the research are summarized as follows:

- The face turning method is a very useful way to understand the machinability of sinter-hardened steels. It is seen that parameters such as cutting speed, feed rate, and cutting depth have a significant effect in order to enable PM steels to be cut with good performance.

- The surface quality is sensitive to variations of all cutting parameters used in the study. The increase of cutting speed has a positive effect on surface quality, in other words, it causes the decrease in surface roughness values. Increased feed rate and cutting depth adversely affect surface quality. The combination of low feed rate and cutting depth at high cutting speeds is a suitable parameter for minimum surface roughness.

- In turning operations, the most effective parameter in chip size is cutting speed, and the second one is cutting depth. The least effective parameter is feed rate. The influence of the cutting parameters on the chip shape is negligible.

- Higher feed rates and cutting depth increase the forces and deteriorate surface finish. An increase in cutting speed increases the forces and, however, has a positive effect on the surface finish. Surface roughness and cutting force decrease by the increase in cutting speed; however, it increases wear of the cutting tool. The increase in the cutting speed results in higher flank wear but improves surface finish. It means that the highest speed, which gives acceptable surface, should be selected.

- It was determined that the surface quality of the machined sinter-hardened PM parts will be positively affected by the selection of appropriate cutting parameters. The quality of machinability at PM sinter hardenable steels used in industrial applications can be improved in a positive way with the combination of the parameters defined in this study.

- The benefit derived from the optimization of cutting parameters will be as best productivity and cost combination as possible for PM sinter-hardened components.

\section{ACKNOWLEDGMENT}

This work was supported by Scientific Research Projects Coordination Unit of Istanbul University, Project number FDK-2016-20732. The authors would like to thank Tarkan Yazıcı for his assistance in machining tests and evaluations.

\section{NOMENCLATURE}

$\mathrm{a}$

f Feed rate $[\mathrm{mm} / \mathrm{rev}]$

$V \quad$ Cutting speed $[\mathrm{m} / \mathrm{s}]$

$T \quad$ Tool life [minute]

$R^{2} \quad$ R-squared, Goodness of fit

$\gamma_{0}$ Rake angle

á Flank angle

$\kappa_{\gamma} \quad$ Cutting edge angle

Fx Axial force 

Fy Cutting force
$\mathrm{Fz} \quad$ Feed force
F Ferrite phase
P Pearlite phase
A Austenite phase
B Bainite phase
M Martensite phase
MP Micropores phase

\section{REFERENCES}

Agapiou, J.S., Halldin, G.W. \& DeVries, M.F. 1988. On the machinability of powder metallurgy austenitic stainless steels. Journal of Engineering for Industry, 110(4): 339-343.

Alizadeh, E. 2008. Factors influencing the machinability of sintered steels. Powder Metallurgy and Metal Ceramics, 47(5-6): 304-315.

Andersson, O. \& Berg, S. 2005. Machining of Chromium-Alloyed PM Steels. International Conference on Powder Metallurgy \& Particulate Materials (PM2TEC 2005), Montreal, 23 June.

Armarego, E.J.A., Shi, G. \& Verezub, S. 2001. Modelling the basic cutting action and machining performance of sintered metallic materials. Machining Science and Technoogy, 5(3): 535-373.

Bekoz, N. 2013. Mechanical Properties of Sinter-Hardened Cu-Ni-Mo Based Steels, PPM 2013 International Porous and Powder Materials Symposium and Exhibition, 3-6 September Cesme-Izmir, Turkey.

Bhushan, R.K., Kumar, S. \& Das, S. 2010. Effect of machining parameters on surface roughness and tool wear for $7075 \mathrm{Al}$ alloy $\mathrm{SiC}$ composite. The International Journal of Advanced Manufacturing Technology, 50(5-8): 459-469.

Blais, C., L'Espérance, G. \& Bourgeois, I. 2001. Characterisation of machinability of sintered steels during drilling operations. Powder Metallurgy, 44(1): 67-76.

Blais, C. \& L'Espérance, G. 2002. Turning and drilling of parts made from sinter hardenable steel powders. Powder Metallurgy, 45(1): 39-47.

Capus, J.M. 1981. Machinability studies with sintered ferrous alloys. SAE Technical Paper Series No. 810246, SAE, Warrendale,PA.

Capus, J. 2013. Forward progress in the machining of PM steel parts. Metal Powder Report, 68(5): 22-24.

Causton, R.J. \& Schade, C. 2003. Machinability: a material property or process response. Advances in Powder Metallurgy and Particulate Materlals, (7): 7-154.

Chambers, A.R. 1996. The machinability of light alloy MMCs. Composites Part A: Applied Science and Manufacturing, 27(2): $143-147$.

Czampa, M., Markos, S. \& Szalay, T. 2013. Improvement of drilling possibilities for machining powder metallurgy materials. Procedia CIRP 7: 288-293.

Desaigues, J.E., Lescalier, C., Bomont-Arzur, A., Dudzinski, D. \& Bomont, O. 2016. Experimental study of built-up layer formation during machining of high strength free-cutting steel. Journal of Materials Processing Technology, 236: 204-215.

Desbiens, J., Robert-Perron, E., Blais, C. \& Chagnon, F. 2012. Effect of green machining on the tensile properties and fatigue strength of powder metallurgy sinter-hardenable steel components. Materials Science and Engineering: A 546: 218-222.

Ebrahimi, A. \& Moshksar, M. M. 2009. Evaluation of machinability in turning of microalloyed and quenched-tempered steels: Tool wear, statistical analysis, chip morphology. Journal of Materials Processing Technology, 209(2): 910-921.

Engström, U. 1983. Machinability of sintered steels. Powder Metallurgy, 26(3): 137-144. 
Gökkaya, H. 2010. The Effects of Machining Parameters on Cutting Forces, Surface Roughness, Built-Up Edge (BUE) and Built-Up Layer (BUL) During Machining AA2014 (T4) Alloy. Strojniski Vestnik Journal of Mechanical Engineering, 56 (9):584-593.

Grzesik, W. \& Nieslony, P. 2000. Thermal characterization of the chip-tool interface when using coated turning inserts. Journal of Manufacturing Processes, 2(2): 79-87.

Hamiuddin, M. \& Murtaza, Q. 2001. Machinability of phosphorous containing sintered steels. Materials Chemistry and Physics 67(1-3): 78-84.

Heidari, M. 2018. Material removal mechanism and surface integrity in ultraprecision cutting of porous materials. Doctoral Thesis, School of Science and Technology, Keio University.

Höganäs, A.B. 2004-a. Handbook for Machining of Sintered Steels: Guideline for Turning, Drilling and Tapping. Höganäs AB, Sweden.

Höganäs, A.B. 2004-b. Höganäs Iron and Steel Powder for Sintered Components. Handbook, Höganäs AB, Sweden.

Höganäs, A.B. 2004-c. Höganäs Handbook for Sintered Components: Metallography. Höganäs AB, Sweden.

Hwang, J.\& Chandrasekar, S. 2011. Contact conditions at the chip-tool interface in machining. International Journal of Precision Engineering and Manufacturing, 12(2): 183-193.

Isik, Y. 2007. Investigating the machinability of tool steels in turning operations. Materials \& Design, 28(5): 1417-1424.

Jakubéczyová, D. \& Fáberová, M. 2002. Mechanical properties and surface treatment PM cobalt high speed steels. Powder Metallurgy Progress (Slovak Republic) 2(3): 188-197.

Jin, D., Liu, Z., Yi, W. \& Su, G. 2011. Influence of cutting speed on surface integrity for powder metallurgy nickel-based superalloy FGH95. The International Journal of Advanced Manufacturing Technology, 56(5-8): 553-559.

Klink, A., Guo, Y.B. \& Klocke, F. 2011. Surface integrity evolution of powder metallurgical tool steel by main cut and finishing trim cuts in wire-EDM. Procedia Engineering, 19: 178-183.

Lalbondre, R., Krishna, P. \& Mohankumar, G.C. 2013. Machinability studies of low alloy steels by face turning method: An experimental investigation. Procedia Engineering, 64: 632-641.

Lindskog, P. 2013. The history of Distaloy. Powder Metallurgy, 56(5): 351-361.

M'Saoubi, R., Czotscher, T., Andersson, O. \& Meyer, D. 2014. Machinability of powder metallurgy steels using PcBN inserts. Procedia CIRP 14: 83-88.

Obikawa, T., Yamaguchi, M., Funai, K., Kamata, Y.\& Yamada, S. 2012. Air jet assisted machining of nickel-base superalloy. International Journal of Machine Tools and Manufacture, 61: 20-26.

Obikawa, T., Ohno, T., Maetani, T. \& Ozaki, Y. 2018. Machining of sintered steel under different lubrication conditions. Machining Science and Technology, 22(2): 338-352.

Ozcatalbas, Y. 2003-a. Chip and built-up edge formation in the machining of in situ Al4C3-Al composite. Materials \& Design, 24(3): 215-221.

Ozcatalbas, Y. 2003-b. Investigation of the machinability behaviour of $\mathrm{Al}_{4} \mathrm{C}_{3}$ reinforced Al-based composite produced by mechanical alloying technique. Composites Science and Technology, 63(1): 53-61.

Ozcatalbas, Y. 2014. Machinability of Elongated Coarse Grain Fe-Based Superalloys. Machining Science and Technology, 18(4): 626-637.

Robert-Perron, E., Blais, C., Thomas, Y., Pelletier, S. \& Dionne, M. 2005. An integrated approach to the characterization of powder metallurgy components performance during green machining. Materials Science and Engineering: A 402 (1-2): 325-334.

Robert-Perron, E., Blais, C., Pelletier, S. \& Thomas, Y. 2007-a. Machinability of green powder metallurgy components: part I. characterization of the Influence of tool wear. Metallurgical and Materials Transactions A 38 (6): 1330-1336.

Robert-Perron, E., Blais, C., Pelletier, S. \& Thomas, Y. 2007-b. Drilling of high quality features in green powder metallurgy components. Materials Science and Engineering: A 458 (1-2): 195-201. 
Robert-Perron E., Blais, C., Pelletier, S., Thomas. Y. \& St-Laurent, S. 2007-c. Chip reclamation in green machining for highperformance PM components. International Journal of Powder Metalllurgy, 43:49-55.

Saini, S., Ahuja, I.S. \& Sharma, V.S. 2012. Influence of cutting parameters on tool wear and surface roughness in hard turning of AISI H11 tool steel using ceramic tools. International Journal of Precision Engineering and Manufacturing, 13(8): 12951302.

Šalak, A., Selecká, M. \& Danninger, H. 2005. Machinability of Powder Metallurgy Steels. Cambridge Int Science Publishing.

Šalak, A., Vasilko, K., Selecká, M. \& Danninger, H. 2006. New short time face turning method for testing the machinability of PM steels. Journal of Materials Processing Technology, 176(1-3): 62-69.

Selvakumar, N., Raj, A.P.M. \& Narayanasamy, R. 2012. Experimental investigation on workability and strain hardening behaviour of Fe-C-0.5 Mn sintered composites. Materials \& Design, 41: 349-357.

Smith, G.T. 1988. Drilled hole quality assessment in ferrous PM components using surface integrity techniques. Powder Metallurgy 31(2): 117-125.

Tambani, M.T., Machio, C., Madyira, D.M., Uheida, E.H. \& Oosthuizen, G.A. 2018. A study of the machinability of Ti-6Al-4V compacted powders. IOP Conference Series: Materials Science and Engineering, 430(1): 12014.

Trent, E.M. \& Wright, P.K. 2000. Metal Cutting. Butterworth-Heinemann.

Ye, G.G., Xue, S.F., Ma, W., Jiang, M.Q., Ling, Z., Tong, X.H. \& Dai, L.H. 2012. Cutting AISI 1045 steel at very high speeds. International Journal of Machine Tools and Manufacture, 56: 1-9.

Zurecki, Z., Frey, J.H. \& Ghosh, R. 2003. Finish-turning of hardened powder-metallurgy steel using cryogenic cooling. Advances in Powder Metallurgy and Particulate Materials, (7): 7-185. 